Article

\title{
Fungal Pretreatments on Non-Sterile Solid Digestate to Enhance Methane Yield and the Sustainability of Anaerobic Digestion
}

\author{
Andrea Zanellati ${ }^{1}$ (D) Federica Spina ${ }^{1}\left(\mathbb{D}\right.$, Luca Rollé ${ }^{2}$, Giovanna Cristina Varese ${ }^{1, *(1)}$ \\ and Elio Dinuccio $2, *$ (D) \\ 1 Mycotheca Universitatis Taurinensis (MUT), Department of Life Sciences and Systems Biology, \\ University of Turin, Viale Mattioli 25, 10125 Turin, Italy; andrea.zanellati@unito.it (A.Z.); \\ federica.spina@unito.it (F.S.) \\ 2 Department of Agriculture, Forestry and Food Science (DISAFA), Mechanics Section, University of Turin, \\ Largo Paolo Braccini 2, 10095 Grugliasco, Italy; lu.rolle@unito.it \\ * Correspondence: cristina.varese@unito.it (G.C.V.); elio.dinuccio@unito.it (E.D.)
}

Received: 2 September 2020; Accepted: 12 October 2020; Published: 15 October 2020

check for updates

\begin{abstract}
Fungi can run feedstock pretreatment to improve the hydrolysis and utilization of recalcitrant lignocellulose-rich biomass during anaerobic digestion (AD). In this study, three fungal strains (Coprinopsis cinerea MUT 6385, Cyclocybe aegerita MUT 5639, Cephalotrichum stemonitis MUT 6326) were inoculated in the non-sterile solid fraction of digestate, with the aim to further (re)use it as a feedstock for AD. The application of fungal pretreatments induced changes in the plant cell wall polymers, and different profiles were observed among strains. Significant increases $(p<0.05)$ in the cumulative biogas and methane yields with respect to the untreated control were observed. The most effective pretreatment was carried out for 20 days with $C$. stemonitis, causing the highest hemicellulose, lignin, and cellulose reduction $(59.3 \%, 9.6 \%$, and $8.2 \%$, respectively); the cumulative biogas and methane production showed a $182 \%$ and $214 \%$ increase, respectively, compared to the untreated control. The increase in AD yields was ascribable both to the addition of fungal biomass, which acted as an organic feedstock, and to the lignocellulose transformation due to fungal activity during pretreatments. The developed technologies have the potential to enhance the anaerobic degradability of solid digestate and untap its biogas potential for a further digestion step, thus allowing an improvement in the environmental and economic sustainability of the AD process and the better management of its by-products.
\end{abstract}

Keywords: digestate; solid fractions (SFDs); lignocellulose; pretreatment; fungi; biogas

\section{Introduction}

The awareness about the environmental damage caused by the massive exploitation of fossil fuels has led to a green revolution in energy production models in favor of environmentally friendly, cost-effective, and sustainable energy systems [1]. Anaerobic digestion (AD) is one of the most attractive technologies to produce renewable energy [2]. It is a multistep biological process that foresees the conversion of organic feedstocks into biogas-i.e., a gaseous mixture of methane (45-70\%), carbon dioxide (25-55\%), and traces of other compounds (nitrogen, oxygen, hydrogen sulfide, and water). Biogas can be burned to obtain heat or steam, but it is commonly used for cogeneration (the production of both heat and electricity) [2].

$\mathrm{AD}$ is a flexible technology since, theoretically, any organic substrate could be exploited as a feedstock [3]. It is thus a captivating technology for the treatment of a wide range of organic wastes [2]. However, the use of some feedstocks is often limited due to the process microbiology, plant technology, 
country legislation, and biomass properties [3]. The feedstock deeply affects the yields and quality of the AD products [4]. Agricultural biogas plants (ABPs) that are more widely diffused in Europe operate in co-digestion with a mixture of zootechnical effluent, energy crops, and agriculture-related residues [2,3]. The increased use of dedicated crops (such as corn, sorghum, rye, etc.) for energy purposes has led to competition with food and feed production and for land use [5]. Nowadays, the use of energy crops is strongly discouraged at European and national regulatory levels. In Italy, the Ministerial Decree 23 June 2016 provided lower subsidies for plants that use crops in order to discourage this practice. Alternative sustainable lignocellulosic biomasses, such as agro-industrial wastes and by-products (corn stover, wheat straw, and rice straw), may contribute to improve the overall sustainability of AD [6].

In addition to biogas, $\mathrm{AD}$ has the potential to produce various by-products as digestate, which mainly contains water, inorganic compounds (e.g., nitrogen, N; phosphorus, P; potassium, K), and undigested organic matter [4]. Although digestate can be managed in its raw form, the liquid and the solid fractions (SFDs) are often mechanically separated to facilitate handling, storage, and transport $[7,8]$. The liquid fraction contains a high amount of $\mathrm{K}$ and ammoniacal $\mathrm{N}$, whereas the SFD is rich in $\mathrm{P}$ and residual fibers [9]. Since plant cell wall polymers (PCWPs), such as cellulose and lignin, undergo little change during $\mathrm{AD}$, they are conveyed from the lignocellulosic feedstocks mainly into the SFD [10]. The fate of digestate fractions commonly involves agricultural purposes, such as in organic fertilizer and soil amendment [11]. However, their safe management and ever-increasing production is posing some issues [4]. A huge amount of digestate is indeed continuously produced but it cannot be used immediately on farmlands due to its stabilization level, crop growth stage, soil type, and the limits posed by the European Nitrate Directive [12-14]. The required storage of digestate usually involves aboveground uncovered tanks, though undesired emission into the atmosphere can still occur due to the presence of undigested organic matter [15-17]. Moreover, the increasing number of ABPs and their confluence in a specific geographical area (e.g., northern Italy) might lead to local oversupply [14] and the need to transport the excess to areas with nutrients deficits, increasing the overall costs of the process [10]. These technical problems ultimately lead to a consistent environmental impact and the loss of energetic efficiency [17].

Innovative and alternative valorization routes for digestate are the next frontier [4]. According to the circular economy approach, the possibility of exploiting the residual undigested organic matter retained in the SFD as a feedstock for ABPs has been hypothesized [4,9,18]. This solution could also improve the economical profitability and environmental efficiency of the AD process, allowing the mitigation of greenhouse gases and ammonia emissions and the concomitant recovery of economically attractive amounts of biogas-methane $[9,10,16]$.

Unfortunately, the SFD from agrozootechnical residues has been widely recognized as a recalcitrant biomass, and its use in biogas production challenges the microbial community involved in AD [19]. Cellulose crystallinity and lignification degree decrease its digestibility and limit the theoretical biogas yields [20]. In order to enhance the anaerobic degradability of refractory biomasses and improve the biogas recovery, pretreatment processes can be applied [21]. Among biological treatments, the use of fungi for feedstock treatment has increasingly gained importance, since they represent a valuable and environmentally sustainable alternative to physicochemical methods [20]. Basidiomycota and Ascomycota are well-known producers of non-stereoselective enzymes that oxidize a wide range of refractory compounds, including lignocellulose complex [20]. Causing mechanical and enzymatic modifications, these fungi could make structural polysaccharides more accessible for AD microorganisms, resulting in an increased biogas yield [20,22]. In the literature, only a few studies have dealt with fungal treatment to make the SFD more susceptible to a further digestion step and valorization. Nowadays, any application at a large scale is prevented by the lack of knowledge about how to control the process, the operative parameters to be monitored, the microbial resources to be exploited, etc. The present work wants to fill this gap, focusing the attention on the characteristics and residual biomethane potential of the SFD and processes that could lead to its (re)use as an AD 
feedstock. This study aims to evaluate the role of pretreatments in order to transform lignocellulose and consequently enhance the methane recovery. Biological techniques based on filamentous fungi were then the tool used to achieve this goal. Three different fungal strains (Coprinopsis cinerea MUT 6385, Cyclocybe aegerita MUT 5639, and Cephalotrichum stemonitis MUT 6326), belonging to the Basidiomycota and Ascomycota phyla, were used. For each strain, the effects of two different pretreatment times (10 and 20 days) were investigated.

\section{Materials and Methods}

\subsection{Biomass Sampling and Storage}

The SFD was collected from a storage facility of a mesophilic full-scale ABP operating in north-west Italy (Piedmont region). The selected ABP was a stirred tank reactor with $1 \mathrm{MWel}$ of installed power fed with maize silage (75\%), triticale silage $(13 \%)$, and other cereals $(12 \%)$. The organic loading rate was $2.25 \mathrm{~kg}$ volatile solids (VS) $\mathrm{m}^{3}$ digester/day. The hydraulic retention time was about 60 days. The resulting digested slurry (approximately $70 \mathrm{t} /$ day) was processed through a screw-press (CRIMAN ${ }^{\circledR}$ mod. SM260) to separate the SFD (about $5 \mathrm{t} /$ day) from the liquid fraction (about $65 \mathrm{t} /$ day). The SFD was dried and N-stripped before storage in a static heap on an uncovered platform.

\subsection{Biomass Characterization}

Homogenous composite samples of untreated and fungal-pretreated SFD were prepared. The total solids (TS), VS, total nitrogen (TN), total ammoniacal nitrogen (TAN), and $\mathrm{pH}$ were analyzed according to the Association of Official Analytical Chemists (AOAC) [23] and Dinuccio et al. [24]. The total fiber composition was estimated as neutral detergent fiber (NDF), acid detergent fiber (ADF), and acid detergent lignin (ADL) using the detergent Van Soest methods [25]. The hemicellulose and cellulose contents were calculated as the difference between the NDF and ADF, and the ADF and ADL, respectively [24]. The TS, TN, and TAN data were expressed as percentages of the raw wet biomass. On the contrary, the VS, NDF, and PCWP data were expressed as percentages of the TS content of the dry biomass, avoiding any bias due to samples with different water contents. The percentage loss of biomass components (TS, VS, NDF, and PCWP) during the fungal pretreatment was calculated according to Zhao et al. [26]. Normalization with the contribution of the fungal biomass $(6.7 \%$ of TS) was not performed because the Van Soest method cannot discriminate between the fungal and plant insoluble components [27].

\subsection{Fungal Pretreatments}

C. cinerea MUT 6385, C. aegerita MUT 5639, and C. stemonitis MUT 6326 were selected as promising candidates to perform the whole cell pretreatment on SFD since, in a preliminary screening, they showed the ability to efficiently colonize the biomass in non-sterile conditions. The strains are preserved at the Mycotheca Universitatis Taurinensis (MUT) of the Department of Life Sciences and Systems Biology, University of Turin (Italy). The nucleotide sequences of C. cinerea MUT 6385 and C. stemonitis MUT 6326 were deposited at the GenBank NCBI database under the accession numbers MT151631 and MT151633, respectively.

Fungi were pre-grown in Malt Extract Agar (MEA: $20 \mathrm{~g} / \mathrm{L}$ of malt extract, $20 \mathrm{~g} / \mathrm{L}$ of glucose, $2 \mathrm{~g} / \mathrm{L}$ of peptone, $18 \mathrm{~g} / \mathrm{L}$ of agar) and incubated at $25^{\circ} \mathrm{C}$ for 10 days. They were then grown in submerged fermentation in $500 \mathrm{~mL}$ Erlenmeyer flasks containing $350 \mathrm{~mL}$ of diluted (1:10) Malt Extract Broth with $10 \mathrm{~g} / \mathrm{L}$ of maize silage. Flasks were incubated at $25^{\circ} \mathrm{C}$ in agitation $(120 \mathrm{rpm})$ in the dark. After 7 days, mycelial pellets were filtered and washed in order to avoid adding to the SFD any component of the exhaust medium and the fungal metabolites produced during the liquid fermentation. The fungal biomasses used as inoculum had an average TS content of $7.3 \%$, of which $97.4 \%$ was VS. Then, $20 \mathrm{~g}$ dry weight $(\mathrm{dw})$ of fungal biomass was inoculated in $300 \mathrm{~g} \mathrm{dw}$ of non-sterilized SFD. Water was added $(2: 3$ ratio $w / v)$ to obtain a final moisture content of about $70-75 \%$, indicated in the literature as optimal 
for lignin decomposition [28]. The inoculated SFD was incubated at $25^{\circ} \mathrm{C}$ for $10-20$ days. According to the literature data $[29,30]$ and preliminary trials, a few weeks of pretreatment is optimal for fungal growth. SFD without fungal inoculum was set up as a negative control. At the end of the aerobic pretreatments, the biomasses were analyzed and used as feedstocks for AD in lab-scale experiments.

\subsection{Biochemical Methane Potential Tests}

Biochemical Methane Potential (BMP) tests were performed through batch trials according to Dinuccio et al. [24] and VDI 4630 [31]. The inoculum was the separated liquid fraction of the digested slurry produced by selected ABP. Batch reactors ( $2 \mathrm{~L})$ were filled with water $(700 \mathrm{~g})$ and a mixture of feedstock and inoculum $(800 \mathrm{~g})$ with a 1:2 ratio based on the VS content. Inside each batch reactor the same amount of VS was added, for a total of $29.1 \mathrm{~g}$ VS. Batches containing untreated SFD were used as a control. Blank batches trials (inoculum only) were also carried out to determine the productivity and correct the yields from the tested biomasses. The potential biogas production derived from the addition of VS from fungal biomass was not compensated, and it was included in the calculations of the final yields. For each trial condition, three replicates were set. Biogas was collected in a Tedlar bag ( $3 \mathrm{~L}$ capacity), connected to the glass taps of each batch reactor by means of tygon tubing. Trials were performed under mesophilic conditions $\left(40 \pm 2{ }^{\circ} \mathrm{C}\right)$ in a climatic chamber for 75 days. The biogas volume and composition were monitored every 4 days for the first 3 weeks and then weekly, until no more biogas production was detected. The volume of biogas produced was measured by means of a Ritter Drum-type gas volume meter (TG05/5, Ritter Apparatebau GmbH and Co. KG, Bochum, Germany). The methane concentration in the biogas was determined with a gas analyzer equipped with infrared sensors (model XAM 7000, Drägerwerk AG and Co. KgaA, Lübeck, Germany). The recorded data were normalized according to VDI 4630 [31] and the specific yields of biogas and methane were expressed as normal liters $\left(\mathrm{L}_{\mathrm{N}}\right)$ per $\mathrm{kg}$ of VS. The daily rate $\left(\mathrm{L}_{\mathrm{N}} / \mathrm{kg} \mathrm{VS} \mathrm{d}\right)$ and cumulative $\left(\Sigma \mathrm{L}_{\mathrm{N}} / \mathrm{kg} \mathrm{VS}\right)$ biogas and methane production were calculated according to the procedure described by Dinuccio et al. [24].

\subsection{Statistical Analyses}

Data of the TS, VS, and cumulative biogas and methane yields were statistically analyzed by a one-way analysis of variance (ANOVA) followed by Tukey's means grouping tests using the software package RStudio Version (3.4.3).

\section{Results}

\subsection{Fungal Inoculum Addition and Pretreatment of SFD}

The chemical characterization of the untreated and fungal-pretreated SFD is presented in Table 1. All the samples showed an alkaline $\mathrm{pH}$ with a negligible TAN content $(0.01 \%)$. Lignocellulosic fibers (NDF) were the major components of organic matter (VS), representing, on average, approximately $80 \%$ of the TS. The hemicellulose content was minimal (1.1-2.7\% of TS), whereas cellulose and insoluble lignin (ADL) were the main fibrous components (around $30 \%$ and $48 \%$ of the TS, respectively).

The fungal inoculum addition and pretreatments greatly affected the SFD. Decreased values of $\mathrm{pH}$ and TN content were observed in comparison with the untreated SFD. Similarly, the TS concentration significantly $(p<0.05)$ decreased $23.8 \%, 25.4 \%$, and $28.5 \%$ in samples pretreated with $C$. aegerita, C. stemonitis, and C. cinerea, respectively. In detail, the addition of water from the fungal inoculum caused an approximately $20.6 \%$ reduction in the TS. On the other hand, the VS content did not change $(p>0.05)$ compared to the untreated controls.

Fungal pretreatments also changed the concentration and composition of the fibers. The percentage of NDF losses ranged from $1.6 \%$ to $10.4 \%$ in samples pretreated with C. cinerea for 10 days and with C. stemonitis for 20 days, respectively. The different strains showed a similar behavior towards the PCWP, causing a higher reduction in hemicellulose (18.5-59.3\%) as compared to lignin (1.0-9.6\%) 
and cellulose (0.2-8.2\%). However, the levels of conversion of each PCWP are different among the strains tested. Noteworthy, the highest reductions in all the PCWP components were obtained with pretreatment with $C$. stemonitis for 20 days, which resulted in $59.3 \%, 9.6 \%$, and $8.2 \%$ hemicellulose, lignin and cellulose reductions, respectively. Compared to C. stemonitis, the Basidiomycota strains gained a lower lignin reduction (1.6-3.2\% and 1.0-3.9\% with 10 and 20 days of pretreatment with C. cinerea and C. aegerita, respectively). The pretreatments with $C$. aegerita achieved lower reductions in cellulose (from $0.2 \%$ to $0.8 \%$ with 10 and 20 days, respectively), while those performed with C. cinerea reached a lower hemicellulose reduction (from $18.5 \%$ to $22.2 \%$ for 10 and 20 days, respectively).

Table 1. Characteristics and fiber compositions of the solid fraction of digestate (SFD), untreated (control) and pretreated with Coprinopsis cinerea, Cyclocybe aegerita, and Cephalotrichum stemonitis for 10 and 20 days $(\mathrm{d})$.

\begin{tabular}{cccccccc}
\hline & \multirow{2}{*}{$\begin{array}{c}\text { Untreated } \\
\text { SFD }\end{array}$} & \multicolumn{7}{c}{ Fungal-Pretreated SFD } \\
\cline { 3 - 8 } & (Control) & \multicolumn{2}{c}{ C. cinerea } & C. aegerita & C. stemonitis \\
\cline { 3 - 8 } & & 10d & 20d & 10d & 20d & 10d & 20d \\
\hline pH & 9.4 & 8.2 & 8.5 & 8.8 & 9.0 & 9.0 & 9.1 \\
TS [\%] & 31.7 & 22.7 & 22.6 & 24.1 & 24.2 & 23.9 & 23.4 \\
Humidity [\%] & 68.3 & 77.3 & 77.4 & 75.9 & 75.8 & 76.1 & 76.6 \\
VS [\% TS] & 88.1 & 87.4 & 87.7 & 88.7 & 88.2 & 87.8 & 89.1 \\
TN [\%] & 0.8 & 0.6 & 0.6 & 0.7 & 0.6 & 0.7 & 0.6 \\
TAN [\%] & 0.01 & 0.01 & 0.01 & 0.01 & 0.01 & 0.01 & 0.01 \\
NDF [\% TS] & 82.4 & 80.6 & 79.9 & 81.1 & 79.7 & 79.6 & 73.8 \\
ADF [\% TS] & 79.7 & 78.4 & 77.8 & 79.3 & 78.1 & 77.7 & 72.7 \\
ADL-Lignin [\% TS] & 31.1 & 30.6 & 30.1 & 30.8 & 29.9 & 29.9 & 28.1 \\
Hemicellulose [\% TS] & 2.7 & 2.2 & 2.1 & 1.8 & 1.6 & 1.9 & 1.1 \\
Cellulose [\% TS] & 48.6 & 47.8 & 47.7 & 48.5 & 48.2 & 47.8 & 44.6 \\
\hline
\end{tabular}

The concentrations of biomass components (TS, VS, NDF, and PCWP) generally decreased as the duration of the pretreatments increased. Most of reductions occurred during the first 10 days, while minor changes were observed when prolonging the pretreatments to 20 days. For instance, $C$. cinerea and C. aegerita exhibited a relatively limited variation in the TS and PCWP content between 10 and 20 days of pretreatment.

\subsection{BMP Tests}

Figure 1 shows the daily biogas production rates and respective methane concentrations of untreated and fungal-pretreated SFD. All the samples showed a similar profile of daily biogas yields, with a peak at day 4 , followed by a progressive decrease, which dropped to zero after about 75 days. The SFD samples inoculated and pretreated with fungi did perform better than the untreated control. In particular, the samples pretreated with $C$. cinerea for 10 days produced the highest daily biogas yield (15.6 $\pm 0.8 \mathrm{~L}_{\mathrm{N}} / \mathrm{kg}$ VS d), which was approximately double with respect to the untreated SFD $\left(8.8 \pm 0.1 \mathrm{~L}_{\mathrm{N}} / \mathrm{kg}\right.$ VS d). The daily methane concentration was comparable among all samples (Figure 1); the profile showed a gradual increase (from about $20-30 \%$ up to $55 \%$ ) during the first 10 days of $A D$, when the plateau was reached and was then maintained until the end of the trials.

At the end of the anaerobic incubation, the cumulative biogas and methane yields from all the SFD samples inoculated and pretreated with fungi were significantly $(p<0.05)$ higher than those of the untreated control (Figure 2). The AD worked better with SFD treated by C. stemonitis for 20 days, which led to approximately three-fold higher biogas and methane yields $(+182 \%$ and $+214 \%$, respectively) than the untreated SFD. Comparable $(p>0.05)$ cumulative biogas yields were achieved with pretreatments by $C$. stemonitis and C. aegerita for 10 days and C. cinerea for 20 days (Figure 2). On the other hand, the cumulative methane produced with $C$. stemonitis was significantly higher $(p<0.05)$ than that obtained with $C$. aegerita and C. cinerea for both 10 and 20 days. 


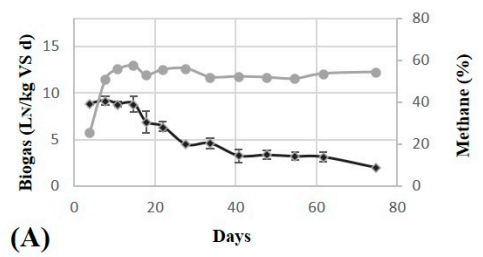

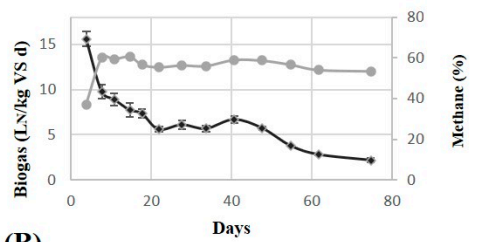

(B)

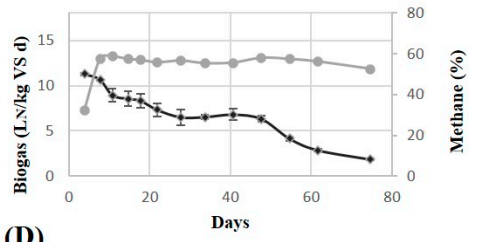

(D)

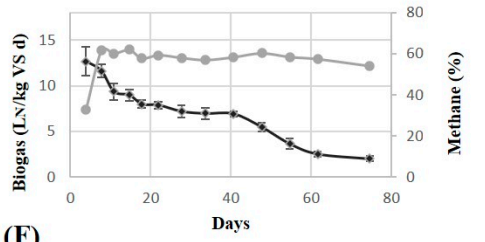

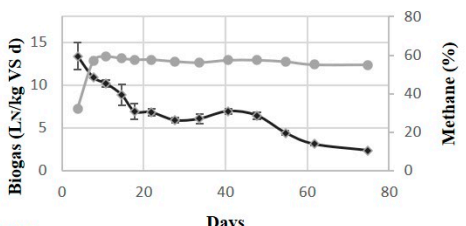

(C)

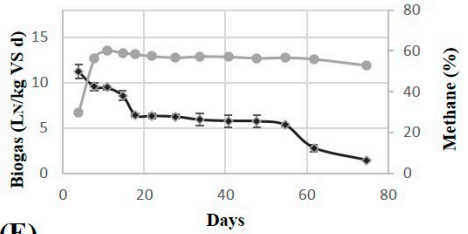

(E)

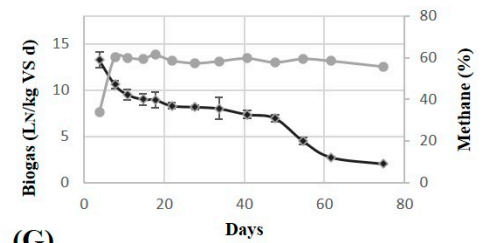

(G)

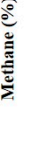

$$
\text { . }
$$


Within a process carried out by the same fungal strain, no significant differences $(p>0.05)$ in the cumulative yields were observed between 10 days and 20 days of pretreatment.

\section{Discussion}

\subsection{SFD Characteristics}

The characteristics and residual biogas potentials of SFD can widely vary according to different parameters, such as the feedstock quality, organic loading rate, hydraulic retention time, storage parameters, and type of separator used on the raw co-digested slurry [4,15]. According to the literature [9,10], the currently studied SFD has an alkaline $\mathrm{pH}(>8)$ (Table 1). Menardo et al. [17] also reported $\mathrm{pH}$ values ranging from 8.6 to 9 for the SFD of three biogas plants treating mainly manure and energy crops. The low TN and TAN concentrations were related to the $\mathrm{N}$-stripping and drying process performed on-site before storage [8]. Biomass alkalinity without the presence of ammonia (TAN) could be a favorable condition for the here-suggested SFD reuse, since it prevents $\mathrm{pH}$ and ammonia inhibition inside the digester tanks [32]. However, excessive alkalinity could represent a limiting factor for biological pretreatment, since the optimum $\mathrm{pH}$ for fungal growth usually ranges around acidic conditions (5 to 6.5) [33]. Moreover, alkaline conditions could be detrimental for enzymatic production and activity, with negative consequences for the PCWP degradation [6].

The observed TS and VS contents (Table 1) were comparable to those reported by Zhong et al. [19], who observed for the SFD from the co-digestion of animal manure and food wastes TS and VS contents of $30.60 \pm 2.13 \%$ and $89.18 \pm 0.29 \%$ on TS, respectively. However, lower VS contents were also found, as reported by Sambusiti [10] ( $83.8 \pm 0.3 \%$ on TS) and Musatti et al. [33] ( $80 \%$ on TS).

In the present study, the SFD was confirmed a recalcitrant biomass, still containing a high organic matter (VS) content (approximately $88 \%$ of TS) due to the presence of not-degraded lignocellulosic fibers (around $80 \%$ of TS), mostly composed of cellulose and lignin. These findings agree with the literature data $[19,33,34]$. It is known indeed that lignin is not biodegradable under anaerobic conditions, while cellulose is degraded at a slower rate than hemicellulose, since cellulose degradation is negatively affected by its degree of crystallinity and interconnection with other PCWPs $[4,33]$. This results in an accumulation of more refractory cellulose and lignin, while hemicellulose can be largely exploited during AD [10]. Considering that the SFD fiber composition mainly depends on the original feedstock pattern [4], the obtained results were not unexpected. In fact, the AD of energy crops (maize silage) usually lead to SFD with a higher cellulose and lignin content and a lower hemicellulose content than that obtained from organic food wastes. For instance, Opatokun et al. [35] reported for the digestate from food wastes a fiber composition characterized by lignin, hemicellulose, and cellulose contents of $13.4 \%, 33.5 \%$ and $32.3 \%$ of TS, respectively. The SFD analyzed by Zhong et al. [19], derived from the co-digestion of animal manure and food-processing wastes, was characterized by a comparable lignin content (30.31\% TS), while the cellulose content was lower $(26.52 \%$ TS) and hemicellulose was higher (13.31\% TS). In comparison with other agro-industrial wastes and by-products exploitable for biogas production, such as wheat straw (lignin $11.2 \%$, hemicellulose $30 \%$, and cellulose $40.2 \%$ ) [36] and rice straw (14.11 $\pm 0.5 \%$ lignin, $27.9 \pm 1.3 \%$ hemicellulose, and $36.3 \pm 1.2 \%$ cellulose) [37], the SFD used in this work was characterized by a higher lignin and cellulose content and a lower hemicellulose content. In general, higher cellulose and hemicellulose contents are desirable, as they constitute the main sources of sugars available from lignocellulosic feedstocks for microorganisms involved in AD [34].

Interestingly, the analyzed SFD showed characteristics (Table 1) comparable and representative of those obtained in most of European mesophilic full-scale ABPs, such as those collected in the regions of northern Italy $[9,10,38]$, which are areas characterized by a local oversupply of digestate [14]. In this context, the importance of SFD (re)use as an AD feedstock is even higher, since it could permit a better and complete exploitation of the original feedstocks into added-value product (methane), contributing to improve the economic and environmental efficiency of the AD process $[4,9]$. 


\subsection{Fungal Inoculum Addition and Pretreatments: Effects on SFD}

The fungal pretreatments performed in this study deeply affected the features of non-sterile SFD (Table 1). It should be considered that the applied method, as with others presented in the literature [27], is not actually capable of discriminating the contribution of fungal and plant insoluble components. Hence, the data presented in Table 1 include a marginal fraction of NDF, ADF, and ADL ascribable to the mycelium. Fungi showed alkaline tolerance, but during the pretreatment they caused a $\mathrm{pH}$ lowering, probably to establish an environmental niche more closely related to their physiological needs (i.e., acidic conditions), including the optimal conditions for their oxidative enzymes to operate [33].

The decreases in TS after the pretreatments were mostly caused by dilution due to the fungal inoculum water content and by PCWP degradation [26,29]. Similar results were obtained by Nuchdang et al. [39] when pretreating lignocellulosic grass with C. cinerea $(27 \%)$. Carrere et al. [40] and Baldrian et al. [41] reported a slightly lower decrease (10-20\%). It is well-known that fungal pretreatments could lead to considerable TS losses, especially in the case of easily degradable substrates. For instance, Liu et al. [42] reported a decrease of up to 55.3\% in the TS content of corn stover silage following fungal pretreatment. Instead, in line with the results obtained in this study, decreases in TS for recalcitrant materials, such as SFD and albizia biomass residues, are generally lower and not so relevant for the efficiency of the AD process $[40,43]$.

Surprisingly, only small variations $(<1 \% ; p>0.05)$ in the VS content were observed among the untreated and fungal-pretreated SFD. Noteworthily, the data reported in the literature showed higher VS losses than those obtained in this work. For instance, Ge et al. [43] described a VS degradation of $11.2 \%$ on albizia chips pretreated with Ceriporiopsis subvermispora. Similar results were also reported by Kainthola et al. [44] with Pleurotus ostreatus and Ganoderma lucidum on rice straw $(17.2 \%$ and $11.6 \%$ VS loss, respectively). Since an excessive VS degradation during pretreatment could negatively affect the AD process, leading to lower biogas production [44], it was fundamental for pretreatment success to find suitable microorganisms and experimental conditions that allowed the reduction in these losses [40]. Interestingly, samples pretreated with C. cinerea and C. stemonitis had a slightly $(p>0.05)$ increased VS content, probably due to fungal growth and metabolism. After 10 days, the fungi seemed to consume easily degradable compounds (i.e., hemicellulose) together with the more recalcitrant PCWP (lignin and cellulose) to sustain their growth and metabolism, lowering the TS and VS content of SFD. When the pretreatment lasted longer, the VS losses accountable to fungal degradation of PCWP may have been compensated by the grown mycelial biomass, causing the increase in the overall VS content.

All the tested strains affected the PCWP composition. This was not completely unexpected, since the selected fungal strains may produce lignocellulolytic enzymes $[39,45,46]$ potentially useful for improving the bioconversion of lignocellulosic feedstocks [47]. As expected, distinct fungal species caused a different degradation profile and a longer treatment caused major PCWP modifications. The easily accessible hemicellulose was the main target by all strains and the reductions obtained fall within the range of those observed in the literature. For instance, Nuchdang et al. [39] reported the ability of $C$. cinerea to reach a hemicellulose degradation of $27 \%$ on lignocellulosic grass. Similar results were reported for P. ostreatus and Trichoderma reesei on rice straw, which reduced the hemicellulose content by about $23 \%$ [29]. In the work of Isikhuemhen et al. [46], C. aegerita appears to degrade hemicellulose components from $14 \%$ to $53.9 \%$, depending on the combinations of solid waste from digester effluent, wheat straw, and millet used as substrate. C. stemontis showed the highest levels of hemicellulose degradation, even higher than those obtained in the literature with well-known white-rot fungi. For example, Zhi and Wang [36] and Liu et al. [42] obtained with P. chrysosporium a hemicellulose degradation rate lower than $50 \%$ on wheat straw and corn stover silage $(31.2 \%$ and $32.4-48.4 \%$, respectively). Chen et al. [48] stated that some levels of hemicellulose removal can enhance digestibility, since the process increases the porosity of lignocellulosic material. However, an excessive degradation of this heteropolymer can lead to a decrease in the biogas yields, as it is a fundamental 
source of AD microorganisms [20,34]. Considering the initial poor hemicellulose content in SFD, the relatively high losses obtained in this study could be neglectable for the downstream AD process.

The more recalcitrant and abundant lignin and cellulose were also reduced by all fungi, but less efficiently compared to hemicellulose. When comparing the different strains, the SFD pretreated with $C$. aegerita and $C$. cinerea showed the lowest lignin reduction. A similar result was reported by Nuchdang et al. [39], which observed that lignin degradation of lignocellulosic grass treated with C. cinerea was not significantly different from that obtained by natural decay. Isikhuemhen et al. [46] reported variable levels of delignification for C. aegerita, obtaining values similar to those observed in this work $(0.6 \%)$ and values far higher $(21.8 \%)$, depending on the mix of substrates used. Although Basidiomycota species are reported as the most powerful organisms in delignification [20], the pretreatment with Ascomycota C. stemonitis leads to an almost triple delignification compared to C. cinerea and C. aegerita strains. However, the maximum lignin reduction obtained with $C$. stemonitis $(9.6 \%)$ was relatively scarce respect to data reported in literature. For instance, Ge et al. [43] obtained a delignification rate of $24 \%$ pretreating albizia chips with C. subvermispora. Zhi and Wang [36] reported that Phanerochaete chrysosporium was able to reduce wheat straw lignin content by $36 \%$. A higher delignification rate $(35.3 \%)$ was described also by Mustafa et al. [29], pretreating rice straw with P. ostreatus. However, according to Muthangya et al. [49], even a small depletion of lignin may lead to a significant increase in methane production during subsequent AD. In fact, lignin degradation is reported as the main factor for a successful fungal pretreatment, as it increases the accessibility of AD microorganisms to the more easily degradable structural carbohydrates and directly contribute to the enhancement of anaerobic digestibility [26].

Notably, the cellulose reduction rates obtained in this study were lower than those generally described in the literature. For instance, Nuchdang et al. [39] reported a 16\% cellulose degradation for $C$. cinerea grown on lignocellulosic grass. Higher cellulose reductions (ranging from 27.7 to $55.2 \%$ ) were described also by Isikhuemhen et al. [46] using C. aegerita. Conversely, lower cellulose losses, comparable to those obtained in this study, were reported using specific Basidiomycota characterized by a selective delignification system. For example, Wan and $\mathrm{Li}[28]$ reported that $C$. subvermispora lacks a complete cellulolytic system, thus produces negligible cellulose degradation $(<5 \%)$ in all the different lignocellulosic substrates tested. Low cellulose decomposition rates are generally desirable when operating pretreatment processes, as this polysaccharide constitutes one of the main sources of sugars for microorganisms involved in AD [20,34].

On the whole, the changes in SFD can be ascribable both to the addition of fungal biomass and to the fungal activity during pretreatment. As also indicated by literature data [47], the PCWP modifications could increase the digestibility of SFD during AD. However, the heterogenicity of lignocellulosic biomass and the complicated nature of $\mathrm{AD}$ prevent to predict the performance of the process solely based on the composition of feedstocks [50]. In this work, BMP tests in batches were carried out to assess the actual effect of fungal pretreatments on biogas and methane production.

\subsection{BMP Tests}

The results obtained in the BMP tests highlighted that SFD still contains residual biogas and methane potential, confirming that it could be a suitable feedstock for biogas plant feeding [17]. However, the poor biogas and methane yields obtained from the untreated samples (Figure 2) confirmed that a large fraction of SFD organic matter is not readily biodegradable as lack of easily degradable carbon source. The fungal pretreatments were capable of increasing SFD hydrolysis and $\mathrm{BMP}$ yields during the subsequent AD. The improved digestibility can be explained mainly to the reduced biomass recalcitrance caused by the PCWP degradation (Table 1). A higher level of PCWP degradation seems indeed correlated with higher biogas and methane production. However, the fungal biomass added to the system may have also played a role. In fact, the fungal biomass contains lipids, proteins, and other molecules that may boost the microorganisms involved in $\mathrm{AD}$. As demonstrated by Hom-Diaz et al. [51], exhausted fungal biomass could be profitably used as a substrate in AD 
processes, producing 281-595 L methane/kg VS. Jasko et al. [52] tested the BMP of fungal biomass of Paxillus involutus and Phaeolus schweinitzii and they obtained a biogas production of $607.3 \mathrm{~L} / \mathrm{kg}$ VS and $137.9 \mathrm{~L} / \mathrm{kg}$ VS, respectively. The difference between the results obtained with different fungal strains was accounted to the difference in VS composition or to the production of bioactive compounds able to inhibit or enhance the AD process [52]. In this study, considering the average methane productivity reported in literature per $g$ of fungal VS (about $382.5 \pm 169.2 \mathrm{~mL} / \mathrm{g} \mathrm{VS}$ ) [51,52] and the amount of fungal VS introduced inside each batch reactor $(0.71 \mathrm{~g} \mathrm{VS})$, the fungal biomass could have contributed to approximately $5-10 \%$ of the total methane productivity.

In the literature, the time of pretreatment is reported as one of the most critical factors for the efficiency of AD performance [53]. Mustafa et al. [29] treated rice straw for 10, 20, and 30 days with P. ostreatus and T. reesei; the best process performances were obtained with 20 days pretreatment, with higher biogas and methane yields. Shorter incubation times did not degrade enough PCWP, while a longer period would lead to excessive organic matter losses [29]. Different results were obtained by Phutela et al. [30] treating rice straw with T. reesei and Coriolus versicolor for 5, 10, 15, 20, and 25 days. The best treatment last 10 days, while in the other cases, the biogas and methane yields decreased (up to $50.90 \%$ on day 25). Surprisingly, in this work no significant $(p>0.05)$ differences were observed in the cumulative biogas and methane yields between 10 days and 20 days of processing. It would probably take longer to see significant differences, but longer treatment times could cause a decrease in the biogas production during $\mathrm{AD}[40,49]$. Considering that one disadvantage of biological pretreatments is that they are often time consuming [22], it is a positive finding that the developed process allowed us to obtain a significant increase in the $\mathrm{AD}$ yields also with relatively short pretreatment times (10 days).

The use of different fungal strains and species for pretreatment turned out to be the most important factor affecting the $\mathrm{AD}$ performance, with $\mathrm{C}$. stemonitis producing almost triple cumulative biogas and methane with respect to the untreated samples (Figure 2). In comparison with other authors who performed fungal pretreatments on digestate and other recalcitrant biomass, the improvement in biogas and methane yields obtained in this study were far higher and, therefore, encouraging. For instance, Lopez et al. [47] concluded that the treatment of lignocellulosic anaerobic digestate with the white-rot fungus Phanerochaete flavido-alba was not useful to increase the biogas production. Bremond et al. [54] tested on solid digestate the effectiveness of two different Basidiomycota strains (P. ostreatus and Stropharia rugoso-annulata), but the experimental conditions were not optimized and led to uncontrolled organic matter losses and subsequent decreases in the methane yield (up to 50\%). Liu et al. [42] treated corn stover with $P$. chrysosporium and obtained an improvement of biogas production by $10.5 \%$ to $19.7 \%$ and methane yield by $11.7 \%$ to $21.2 \%$, though a pretreatment duration that was longer (30 days). Similarly, Phutela et al. [30] reported an augmentation in biogas yields of $20.8 \%$ and $26.2 \%$ treating rice straw with T. reesei and Coriolus versicolor, respectively.

It should be noted that most of the literature work on the pretreatment of lignocellulosic feedstocks is focused on white-rot basidiomycetes inhabiting wood. The Ascomycota and fungi of other taxonomic groups or habitats have only scarcely been investigated [55]. According to our results, Ascomycota species could be equally able or even more competent in disrupting recalcitrant PCWP and enhance $\mathrm{AD}$ yields. Indeed, $C$. stemonitis was the most efficient in reducing hemicellulose, lignin, and cellulose and increasing the $\mathrm{AD}$ yields. Other authors also confirmed the effectiveness of fungal pretreatments performed with Ascomycota. For instance, the works of Mutschlechner et al. [53], Wagner et al. [56], and Deng et al. [57], reported a significant increase in the biogas yields when pretreating biowaste with Trichoderma species. Unfortunately, studies on Ascomycota focusing mainly on a restricted number of taxa (e.g., Trichoderma and Aspergillus), while this work demonstrated that it would be worthy to expand the research to other potentially suitable fungal species. At present, poor information is available on the potential of $C$. stemonitis to improve the AD bioconversion of lignocellulosic biomass. The findings emphasize the importance of investigating fungal biodiversity to identify new and promising species suitable for the development of effective pretreatment processes. 
Previous studies $[10,38]$ have investigated physical and chemical pretreatments to get a higher energy recovery from SFD, but surprisingly they often obtained poor results compared to those that are here reported. For example, Sambusiti et al. [10] revealed that thermal and alkaline treatments did not have a beneficial effect in enhancing the methane potentials of SFD, while enzymatic treatment resulted in an increase in the methane yield of only 13\%. Menardo et al. [38] assessed in four different mechanically separated SFDs the effects of a thermal pretreatment, and they obtained no statistically significant effect on the daily yields of thermal pretreated samples, but reported a significant increase in the cumulative methane yields that ranged from $35 \%$ to $171 \%$ depending on nature of the organic matter of the considered samples. Cumulative biogas increments of $165 \%$ were reported by Mustafa et al. [58] using on rice straw a combination of physical and biological pretreatments (i.e., milling and fungal pretreatment with P. ostreatus). However, the beneficial income gained from the enhanced biogas yields need to be evaluated together with the higher energy requirements, operational costs, and environmental issues linked to abiotic pretreatments.

In lab-scale experiments, the sterilization of feedstocks is a routine step prior to fungal pretreatment to kill indigenous undesired microbes and assure inoculated microorganisms the best working conditions. However, sterilization is extremely expensive and requires additional energy, materials, and time, preventing its application to an industrial-scale level [26,40]. The proposed technology, which directly uses fungal inocula to pretreat unsterilized biomass, represents a fundamental advantage for future industrial application [26]. Despite the fact that this process developed in non-sterile conditions would allow an easier scale-up and a reduction in the productivity expenditure, very few works about it can be found in the literature. Moreover, pretreatments applied on unsterilized substrates are often destined to fail, since it is extremely challenging to set the optimal conditions necessary to get an efficient colonization and to keep inoculated fungi prevailing over indigenous microflora $[20,26]$. For instance, the pretreatment performed by Zhao et al. [26] on unsterilized yard trimmings inoculated with C. subvermispora was unsuccessful. Similar results were also described by Reid [59], who used Phlebia tremellosa to inoculate unsterilized aspen wood. The results reported by these authors and obtained in this study emphasize the key role played by the right experimental set up, working condition, and type and origin of the feedstock in pretreatment success.

\section{Conclusions}

Considering the low inputs and risks, the developed biological treatments appear to be a cost-effective and environmentally friendly technology to ultimately makes the SFD more susceptible to a further digestion step and increase its biogas and methane yields. Favoring the (re)use of SFD as a feedstock for $\mathrm{AD}$, the fungal pretreatments contribute to the development of a next-generation by-product management strategy. According to the literature, the reuse of SFD in the anaerobic digester has the potential to improve the total methane production of the ABP by between $4 \%$ and $8 \%$. By significantly enhancing the biogas and methane potentials, the fungal pretreatments of the SFD could permit us to obtain an even higher extra electrical production that could correspond to a significant economical income for ABP owners.

New questions have been arisen, such as the precise contribution of the fungal biomass itself to the AD process. The literature is scarce, creating a lack of knowledge that must be filled with targeted investigations. The exploitation of spent fungal biomass as AD feedstocks would bring benefits in terms of renewable energy production and sustainable waste disposal, since it is produced in large volumes by many industrial processes.

Ultimately, the integration of the fungal pretreatment of SFD and its subsequent reuse in the anaerobic digester has the potential to allow greenhouse gaseous loss abatement and concurrent energy recovery, leading to environmental and economic benefits that make the overall sustainability of AD technology even more attractive and effective.

Author Contributions: Conceptualization, A.Z., F.S., L.R., G.C.V., and E.D.; Data curation, A.Z.; Formal analysis, A.Z.; Funding acquisition, G.C.V. and E.D.; Investigation, A.Z.; Methodology, A.Z., F.S., and L.R.; Project 
administration, G.C.V. and E.D.; Resources, G.C.V. and E.D.; Software, A.Z. and L.R.; Validation, F.S., L.R., G.C.V., and E.D.; Visualization, A.Z.; writing-original draft, A.Z.; writing—review and editing, F.S., G.C.V., and E.D. All authors have read and agreed to the published version of the manuscript.

Funding: This research received no external funding.

Acknowledgments: The authors would like to thank the biogas plants owners for allowing the sampling of biomasses. The technical assistance of MUT staff and Giulia Blanchi is greatly acknowledged. A special thanks to the JRU MIRRI-IT for the technical and scientific support.

Conflicts of Interest: The authors declare no conflict of interest.

\section{References}

1. Liguori, R.; Faraco, V. Biological processes for advancing lignocellulosic waste biorefinery by advocating circular economy. Bioresour. Technol. 2016, 215, 13-20. [CrossRef]

2. Vasco-Correa, J.; Khanal, S.; Manandhar, A.; Shah, A. Anaerobic digestion for bioenergy production: Global status, environmental and techno-economic implications, and government policies. Bioresour. Technol. 2018, 247, 1015-1026. [CrossRef] [PubMed]

3. Weiland, P. Biogas production: Current state and perspectives. Appl. Microbiol. Biotechnol. 2010, 85, 849-860. [CrossRef] [PubMed]

4. Monlau, F.; Sambusiti, C.; Ficara, E.; Aboulkas, A.; Barakat, A.; Carrère, H. New opportunities for agricultural digestate valorization: Current situation and perspectives. Energy Environ. Sci. 2015, 8, 2600-2621. [CrossRef]

5. Fritsche, U.R.; Sims, R.E.H.; Monti, A. Direct and indirect land-use competition issues for energy crops and their sustainable production-An overview. Biofuels Bioprod. Biorefining 2010, 4, 692-704. [CrossRef]

6. Young, D.; Dollhofer, V.; Callaghan, T.M.; Reitberger, S.; Lebuhn, M.; Benz, J.P. Isolation, identification and characterization of lignocellulolytic aerobic and anaerobic fungi in one- and two-phase biogas plants. Bioresour. Technol. 2018, 268, 470-479. [CrossRef]

7. Popovic, O.; Gioelli, F.; Dinuccio, E.; Rollè, L.; Balsari, P. Centrifugation of digestate: The effect of chitosan on separation efficiency. Sustainability 2017, 9, 2032. [CrossRef]

8. Guilayn, F.; Jimenez, J.; Rouez, M.; Crest, M.; Patureau, D. Digestate mechanical separation: Efficiency profiles based on anaerobic digestion feedstock and equipment choice. Bioresour. Technol. 2019, 274, 180-189. [CrossRef]

9. Dinuccio, E.; Gioelli, F.; Cuk, D.; Rollè, L.; Balsari, P. The use of co-digested solid fraction as feedstock for biogas plants. J. Agric. Eng. 2013, 44, 3-8. [CrossRef]

10. Sambusiti, C.; Monlau, F.; Ficara, E.; Musatti, A.; Rollini, M.; Barakat, A.; Malpei, F. Comparison of various post-treatments for recovering methane from agricultural digestate. Fuel Process. Technol. 2015, 137, 359-365. [CrossRef]

11. Nkoa, R. Agricultural benefits and environmental risks of soil fertilization with anaerobic digestates: A review. Agron. Sustain. Dev. 2014, 34, 473-492. [CrossRef]

12. Paavola, T.; Rintala, J. Effects of storage on characteristics and hygienic quality of digestates from four co-digestion concepts of manure and biowaste. Bioresour. Technol. 2008, 99, 7041-7050. [CrossRef]

13. Holm-Nielsen, J.B.; Al Seadi, T.; Oleskowicz-Popiel, P. The future of anaerobic digestion and biogas utilization. Bioresour. Technol. 2009, 100, 5478-5484. [CrossRef] [PubMed]

14. Bartoli, A.; Cavicchioli, D.; Kremmydas, D.; Rozakis, S.; Olper, A. The impact of different energy policy options on feedstock price and land demand for maize silage: The case of biogas in Lombardy. Energy Policy 2016, 96, 351-363. [CrossRef]

15. Hansen, T.L.; Sommer, S.G.; Gabriel, S.; Christensen, T.H. Methane Production during Storage of Anaerobically Digested Municipal Organic Waste. J. Environ. Qual. 2006, 35, 830-836. [CrossRef]

16. Gioelli, F.; Dinuccio, E.; Balsari, P. Residual biogas potential from the storage tanks of non-separated digestate and digested liquid fraction. Bioresour. Technol. 2011, 102, 10248-10251. [CrossRef]

17. Menardo, S.; Gioelli, F.; Balsari, P. The methane yield of digestate: Effect of organic loading rate, hydraulic retention time, and plant feeding. Bioresour. Technol. 2011, 102, 2348-2351. [CrossRef]

18. Balsari, P.; Gioelli, F.; Menardo, S.; Paschetta, E. The (re)use of mechanical separated solid fraction of digested or not digested slurry in anaerobic digestion plants. In Proceedings of the 14th Ramiran International Conference, Lisboa, Portugal, 12-15 September 2010; Volume 4630, pp. 2-5. 
19. Zhong, Y.; Liu, Z.; Isaguirre, C.; Liu, Y.; Liao, W. Fungal fermentation on anaerobic digestate for lipid-based biofuel production. Biotechnol. Biofuels 2016, 9, 253. [CrossRef]

20. Rouches, E.; Herpoël-Gimbert, I.; Steyer, J.P.; Carrere, H. Improvement of anaerobic degradation by white-rot fungi pretreatment of lignocellulosic biomass: A review. Renew. Sustain. Energy Rev. 2016, 59, 179-198. [CrossRef]

21. Akhtar, N.; Gupta, K.; Goyal, D.; Goyal, A. Recent advances in pretreatment technologies for efficient hydrolysis of lignocellulosic biomass. Environ. Prog. Sustain. Energy 2016, 35, 489-511. [CrossRef]

22. Merlin Christy, P.; Gopinath, L.R.; Divya, D. A review on anaerobic decomposition and enhancement of biogas production through enzymes and microorganisms. Renew. Sustain. Energy Rev. 2014, 34, 167-173. [CrossRef]

23. AOAC. Official Methods of Analysis, Association of Analytical Chemists, 15th ed.; AOAC: Washington, DC, USA, 2000. [CrossRef]

24. Dinuccio, E.; Balsari, P.; Gioelli, F.; Menardo, S. Evaluation of the biogas productivity potential of some Italian agro-industrial biomasses. Bioresour. Technol. 2010, 101, 3780-3783. [CrossRef]

25. Van Soest, P.J.; Robertson, J.B.; Lewis, B.A. Methods for Dietary Fiber, Neutral Detergent Fiber, and Nonstarch Polysaccharides in Relation to Animal Nutrition. J. Dairy Sci. 1991, 74, 3583-3597. [CrossRef]

26. Zhao, J.; Ge, X.; Vasco-Correa, J.; Li, Y. Fungal pretreatment of unsterilized yard trimmings for enhanced methane production by solid-state anaerobic digestion. Bioresour. Technol. 2014, 158, 248-252. [CrossRef] [PubMed]

27. Nayan, N.; van Erven, G.; Kabel, M.A.; Sonnenberg, A.S.M.; Hendriks, W.H.; Cone, J.W. Evaluation of fungal degradation of wheat straw cell wall using different analytical methods from ruminant nutrition perspective. J. Sci. Food Agric. 2019, 99, 4054-4062. [CrossRef]

28. Wan, C.; Li, Y. Effectiveness of microbial pretreatment by Ceriporiopsis subvermispora on different biomass feedstocks. Bioresour. Technol. 2011, 102, 7507-7512. [CrossRef] [PubMed]

29. Mustafa, A.M.; Poulsen, T.G.; Sheng, K. Fungal pretreatment of rice straw with Pleurotus ostreatus and Trichoderma reesei to enhance methane production under solid-state anaerobic digestion. Appl. Energy 2016, 180, 661-671. [CrossRef]

30. Phutela, U.G.; Sahni, N.; Sooch, S.S. Fungal degradation of paddy straw for enhancing biogas production. Indian J. Sci. Technol. 2011, 4, 660-665. [CrossRef]

31. Verein Deutscher Ingenieure (VDI) 4630. Fermentation of Organic Materials-Characterisation of the Substrate, Sampling, Collection of Material Data, Fermentation Tests; VDI Handbuch Energietechnik; Beuth Verlag GmbH: Berlin, Germany, 2006; pp. 44-59.

32. Yang, Z.; Wang, W.; He, Y.; Zhang, R.; Liu, G. Effect of ammonia on methane production, methanogenesis pathway, microbial community and reactor performance under mesophilic and thermophilic conditions. Renew. Energy 2018, 125, 915-925. [CrossRef]

33. Musatti, A.; Ficara, E.; Mapelli, C.; Sambusiti, C.; Rollini, M. Use of solid digestate for lignocellulolytic enzymes production through submerged fungal fermentation. J. Environ. Manag. 2017, 199, 1-6. [CrossRef] [PubMed]

34. Vasco-Correa, J.; Ge, X.; Li, Y. Fungal pretreatment of non-sterile miscanthus for enhanced enzymatic hydrolysis. Bioresour. Technol. 2016, 203, 118-123. [CrossRef] [PubMed]

35. Opatokun, S.A.; Kan, T.; Al Shoaibi, A.; Srinivasakannan, C.; Strezov, V. Characterization of Food Waste and Its Digestate as Feedstock for Thermochemical Processing. Energy Fuels 2016, 30, 1589-1597. [CrossRef]

36. Zhi, Z.; Wang, H. White-rot fungal pretreatment of wheat straw with Phanerochaete chrysosporium for biohydrogen production: Simultaneous saccharification and fermentation. Bioprocess Biosyst. Eng. 2014, 37, 1447-1458. [CrossRef] [PubMed]

37. Kainthola, J.; Shariq, M.; Kalamdhad, A.S.; Goud, V.V. Enhanced methane potential of rice straw with microwave assisted pretreatment and its kinetic analysis. J. Environ. Manag. 2019, 232, 188-196. [CrossRef] [PubMed]

38. Menardo, S.; Balsari, P.; Dinuccio, E.; Gioelli, F. Thermal pre-treatment of solid fraction from mechanically-separated raw and digested slurry to increase methane yield. Bioresour. Technol. 2011, 102, 2026-2032. [CrossRef] [PubMed] 
39. Nuchdang, S.; Vatanyoopaisarn, S.; Phalakornkule, C. Effectiveness of fungal treatment by Coprinopsis cinerea and Polyporus tricholoma on degradation and methane yields of lignocellulosic grass. Int. Biodeterior. Biodegrad. 2015, 104, 38-45. [CrossRef]

40. Carrere, H.; Antonopoulou, G.; Affes, R.; Passos, F.; Battimelli, A.; Lyberatos, G.; Ferrer, I. Review of feedstock pretreatment strategies for improved anaerobic digestion: From lab-scale research to full-scale application. Bioresour. Technol. 2016, 199, 386-397. [CrossRef] [PubMed]

41. Baldrian, P.; Valášková, V.; Merhautová, V.; Gabriel, J. Degradation of lignocellulose by Pleurotus ostreatus in the presence of copper, manganese, lead and zinc. Res. Microbiol. 2005, 156, 670-676. [CrossRef]

42. Liu, S.; Wu, S.; Pang, C.; Li, W.; Dong, R. Microbial pretreatment of corn stovers by solid-state cultivation of Phanerochaete chrysosporium for biogas production. Appl. Biochem. Biotechnol. 2014, 172, 1365-1376. [CrossRef]

43. Ge, X.; Matsumoto, T.; Keith, L.; Li, Y. Fungal pretreatment of albizia chips for enhanced biogas production by solid-state anaerobic digestion. Energy Fuels 2015, 29, 200-204. [CrossRef]

44. Kainthola, J.; Kalamdhad, A.S.; Goud, V.V.; Goel, R. Fungal pretreatment and associated kinetics of rice straw hydrolysis to accelerate methane yield from anaerobic digestion. Bioresour. Technol. 2019, 286, 121368. [CrossRef]

45. Peterson, R.; Grinyer, J.; Nevalainen, H. Secretome of the coprophilous fungus Doratomyces stemonitis C8, isolated from koala feces. Appl. Environ. Microbiol. 2011, 77, 3793-3801. [CrossRef]

46. Isikhuemhen, O.S.; Mikiashvili, N.A.; Kelkar, V. Application of solid waste from anaerobic digestion of poultry litter in Agrocybe aegerita cultivation: Mushroom production, lignocellulolytic enzymes activity and substrate utilization. Biodegradation 2009, 20, 351-361. [CrossRef]

47. López, M.J.; Suárez-Estrella, F.; Vargas-García, M.C.; López-González, J.A.; Verstichel, S.; Debeer, L.; Wierinck, I.; Moreno, J. Biodelignification of agricultural and forest wastes: Effect on anaerobic digestion. Biomass Bioenergy 2013, 58, 343-349. [CrossRef]

48. Chen, Y.; Sharma-Shivappa, R.R.; Keshwani, D.; Chen, C. Potential of agricultural residues and hay for bioethanol production. Appl. Biochem. Biotechnol. 2007, 142, 276-290. [CrossRef]

49. Muthangya, M.; Mshandete, A.M.; Kivaisi, A.K. Two-stage fungal pre-treatment for improved biogas production from sisal leaf decortication residues. Int. J. Mol. Sci. 2009, 10, 4805-4815. [CrossRef]

50. Liew, L.N.; Shi, J.; Li, Y. Methane production from solid-state anaerobic digestion of lignocellulosic biomass. Biomass Bioenergy 2012, 46, 125-132. [CrossRef]

51. Hom-Diaz, A.; Baldi, F.; Blánquez, P.; Lombardi, L.; Martín-González, L.; Vicent, T. Exhausted Fungal Biomass as a Feedstock for Increasing Methane Production During the Anaerobic Digestion of Organic Wastes. Waste Biomass Valorization 2016, 7, 307-315. [CrossRef]

52. Novel Substrates for Biogas Production: Paxillus involutus and Phaeolus schweinitzii Mushroom Biomass. Available online: https://www.researchgate.net/profile/Janis_Jasko/publication/236844747_Novel_ substrates_for_biogas_production_Paxillus_involutus_and_Phaeolus_schweinitzii_mushroom_biomass/ links/00b7d5195d073455c6000000.pdf (accessed on 11 October 2020).

53. Mutschlechner, M.; Illmer, P.; Wagner, A.O. Biological pre-treatment: Enhancing biogas production using the highly cellulolytic fungus Trichoderma viride. Waste Manag. 2015, 43, 98-107. [CrossRef]

54. Brémond, U.; Bertrandias, A.; Loisel, D.; Jimenez, J.; Steyer, J.P.; Bernet, N.; Carrere, H. Assessment of fungal and thermo-alkaline post-treatments of solid digestate in a recirculation scheme to increase flexibility in feedstocks supply management of biogas plants. Renew. Energy 2020, 149, 641-651. [CrossRef]

55. Singh, S.; Harms, H.; Schlosser, D. Screening of ecologically diverse fungi for their potential to pretreat lignocellulosic bioenergy feedstock. Appl. Microbiol. Biotechnol. 2014, 98, 3355-3370. [CrossRef]

56. Wagner, A.O.; Schwarzenauer, T.; Illmer, P. Improvement of methane generation capacity by aerobic pre-treatment of organic waste with a cellulolytic Trichoderma viride culture. J. Environ. Manag. 2013, 129, 357-360. [CrossRef]

57. Deng, Y.; Dai, B.; Xu, J.; Liu, X.; Xu, J. Anaerobic co-digestion of rice straw and soybean straw to increase biogas production by pretreatment with Trichoderma reesei RUT C30. Environ. Prog. Sustain. Energy 2018, 37, 1050-1057. [CrossRef] 
58. Mustafa, A.M.; Poulsen, T.G.; Xia, Y.; Sheng, K. Combinations of fungal and milling pretreatments for enhancing rice straw biogas production during solid-state anaerobic digestion. Bioresour. Technol. 2017, 224, 174-182. [CrossRef]

59. Reid, I.D. Optimization of solid-state fermentation for selective delignification of aspen wood with Phlebia tremellosa. Enzyme Microb. Technol. 1989, 11, 804-809. [CrossRef]

Publisher's Note: MDPI stays neutral with regard to jurisdictional claims in published maps and institutional affiliations.

(C) 2020 by the authors. Licensee MDPI, Basel, Switzerland. This article is an open access article distributed under the terms and conditions of the Creative Commons Attribution (CC BY) license (http://creativecommons.org/licenses/by/4.0/). 